\title{
Digital economy. IT strategy of the company development
}

\author{
Alexandra D. Borremans ${ }^{1^{*}}$, Irina M. Zaychenko ${ }^{1}$, and Oksana Yu. Iliashenko ${ }^{1}$ \\ ${ }^{1}$ Peter the Great St.Petersburg Polytechnic University, Polytechnicheskaya, 29, St. Petersburg, \\ 195251, Russia
}

\begin{abstract}
The article describes the impact of digital technologies on the level of social and economic development of the society, provides a rating of the largest IT companies in terms of the volume of business capitalization. The necessity of digital transformation of the management of the socio-economic development of society and organizations is substantiated. The problems of transition to a digital basis for managing the economy in the Russian Federation are revealed. The model of IT strategy formation for digital transformation of business processes at the enterprise is formed. As a tool for selecting the most preferred IT strategy of an enterprise in any industry, a matrix of possibilities for implementing an IT strategy for the enterprise is proposed.
\end{abstract}

\section{Introduction}

Nowadays, in order to create competitive company, the high attention should be paid to the new trend of economy development - digital economy. The digital economy is an activity directly related to the development of digital technologies, which includes the provision of online services, electronic payments, e-commerce, crowdfunding. Typically, the main elements of the digital economy are e-commerce, Internet banking, electronic payments, Internet advertising, and Internet games. The digital economy is considered a new basis for the formation and development of various spheres such as banking, retail trade, transportation, electricity, education, health care and many others.

The digital economy is a kind of economy characterized by the active implementation and actual application of digital technologies for the collection, storage, processing, transformation and transmission of data in absolutely all areas of human activity. This is the concept of socio-economic and organizational-technical relationships based on the use of digital information and telecommunication technologies. In addition, this is a complex organizational and technical concept in the form of a set of different elements (industrial, infrastructure, organizational, program, regulatory, legislative, etc.) with distributed interaction and mutual application by economic representatives with the purpose of sharing knowledge in conditions of constant development. The key to the definition of a digital concept is the exchange of knowledge, the technologies that allow it to be done, and a society that can participate in and manage this exchange [1].

\footnotetext{
* Corresponding author: alexandra.borremans@mail.ru
} 
Nowadays, the society enters the era of the digital economy, which significantly changes the habitual areas [2]:

- the main resource is information;

- trading platforms in the Internet are not limited in any way;

- the company does not need to be huge to compete successfully;

- the same material resource can be applied unlimited number of times to provide different services;

- the scale of the operational work is limited only by the scale of the Internet.

The Internet with its colossal potential is considered to be the basic component of the digital economy, increasing efficiency and productivity. The Internet network has established an infrastructure for interaction of various fields of activity. In order to understand how the Internet has a great impact on the digital economy, it is important to understand the scale and geography of its distribution.

In today's economy, digital companies are entering the first plan and are becoming growth points that provide the economy with a digital resource. If in the early twentieth century the main locomotives of the world economy were large oil, metallurgical, engineering and mining companies, today large companies are considered to be representatives of the digital economy sector (Table 1).

Table 1. Rating of the largest companies in the world, 2016 [3]

\begin{tabular}{|c|c|c|}
\hline Company & Main field of activity & Capitalization, \$ \\
\hline Apple & $\begin{array}{c}\text { Manufacture of electronics and information } \\
\text { technology }\end{array}$ & 577,4 billion \\
\hline Google & Internet services, applications, video hosting & YouTube \\
\hline Microsoft & Software production & 547,9 billion \\
\hline Amazon & Trade on the Internet & 443 billion \\
\hline Wells Fargo & Banks & 360 billion \\
\hline Samsung & PC, mobile devices, home appliances and electronics & 299 billion \\
\hline $\begin{array}{c}\text { China } \\
\text { Mobile }\end{array}$ & Telecommunications & 250 billion \\
\hline Verizon & Telecommunications & 229,0 billion \\
\hline AT\&T & Telecommunications & 226,0 billion \\
\hline Walmart & Retail & 216,9 billion \\
\hline
\end{tabular}

Despite the high impact of digital technologies on changing social and economic concepts, the numerous problems of digital transformation remain poorly highlighted. Little attention is paid to the problems of forming digital potential in order to increase the innovative growth of individual companies and areas, the institutional aspects of the digital economy are remained without adequate attention, problems and prospects for forming a business in the conditions of the formation of the digital economy are not adequately covered, the role of the digital economy in the unified concept of modern economic relations is not described properly. For this reason, the goal of this work is to analyze the 
key nuances of the formation of the digital economy and to form judgments about its significance in a single system of economic.

\section{Literature Review and Research Methodology}

\subsection{The concept and essence of the digital economy}

Theoretical understanding of the impact of growing information flows on the current socioeconomic system can be identified in the concepts of the post-industrial and information society. Changes in production processes, the reorientation of manufacturing from the formation of material goods to the provision of services, the globalization of the economy are noted by the theoreticians of the digital community as more fundamental properties of the newest kind of society caused by informatization [4].

Speaking about the process of "digitization" of the economy and society, it is first and foremost necessary to introduce certainty in terminology. In the broadest sense, the process of "digitalization" is usually understood as a socio-economic transformation initiated by the numerous introduction and assimilation of digital technologies, i.e. technologies of formation, processing, exchange and transmission of data.

Today, Russia lives in the digital era. At the moment we cannot imagine the existence of a lack of an Internet network. According to the McKinsey report Digital Russia: New Reality, according to the number of users of the network, the Internet the Russian Federation ranks first in Europe and 6 in the world (87 million people). According to Rosstat statistics, from 2010 to 2016 the number of households with access to the Internet increased from $48.4 \%$ to $74.8 \%$. The Russian Federation takes the 2nd place in the world at the lowest prices for the Internet and mobile communications [5].

In the conditions of digital transformation, the experts are exploring the phenomenon of "economic mobilization" and determining the impact of mobile technologies on the economy of the state. The Russian Association of Electronic Communications in the study "Mobile Economy of the Russian Federation" proves the great contribution and potential of mobile technologies for the economy. To date, the share of the digital economy in total GDP is $5.5 \%$, in developing countries $-4.9 \%$, in China - 6\%, in the Russian Federation $2.8 \%$, the highest in the UK - $12 \%$.

To increase the share of the digital economy in the state, efforts of the authorities, business and science are needed. It is necessary to improve the culture of intensive partnership with educational and research organizations, as well as high-tech firms.

\subsection{Formatting the text}

In order to measure the development of the digital economy, the Organization for Economic Co-operation and Development (OECD) developed a system of indicators [6], which determines the following trends:

- The formation of a high-tech sector of the economy;

- Investment in research, software development, education costs and auxiliary retraining;

- Creation and production of information and communication equipment;

- Formation of working zones in the field of science and high technologies;

- Data of cooperation between corporations, institutions and research organizations; international cooperation in the field of science and innovation;

- The dynamics of the spread of the Internet on the international market. 
In general terms, it is possible to note four criteria for analyzing the digital economy, to varying degrees examined by different researchers:

1. The criterion associated with the sphere of employment;

2. Spatial criterion;

3. Technological criterion;

4. Economic criterion.

Criterion associated with the field of employment is directly related the composition of employment of residents and the model of observed changes. The transformation of socioeconomic relations is due to the fact that most of the employed function in the digital economy. Reduction in the share of employed in the field of production and increase in the sphere of services is seen as a replacement of physical labor by information. Since the main resource in this case is data, a significant increase in the share of labor in their processing can be seen as a transformation to the digital economy. Statistical studies show an increase in the proportion of people engaged in services (in Western Europe, the United States, in Japan, this share reaches $70 \%$ ), a large proportion of which in one way or another involved in the processing of specific information, and therefore quite valid to justify the existence of a digital economy. The main problem of this approach is the difficulty of employees involved in working with data. For example, we can assume that the basis for the formation of the digital economy has been the process of increasing the number of specialists in computer technologies, telecommunications firms, analysts whose main task is processing information.

Several concepts of the digital economy are based on the geographical principle [7]. The main attention is paid to information transmission networks, which unite different zones, and as a result have all chances to influence the development of the world economic space. Information transmission networks are considered an important characteristic feature of the modern community. At the same time, an important factor is what aspect related to information transmission networks is considered in the study of the digital economy. Will this scientific and technical aspect, i.e. the presence of specific concepts for the transfer of information in a particular area, or other aspects, such as the amount of information transmitted over these networks, the quality of these data, etc.

An economic criterion involves calculating the increase in economic value in the sphere of activity in the formation, transmission, processing, storage of information. If in the economic field this kind of dynamism prevails over activities in the field of agriculture and industry, in that case, we can talk about the transition to a digital economy. In addition, the data themselves in such circumstances become the object of economic relations. Specialized companies, research and experimental companies provide services for collecting, analyzing information for the purposes of the client and, according to this, such information acquires some value.

Technological criterion: The basis of the technological concept was a large number of technological innovations in the field of information and communication technologies, which became accessible to a wide circle of users [8]. The newest technologies are considered the most significant indicator of changes in economic concepts, and they are often called the driver of the formation of the economy. The main concept of such reasoning is that the increased size of technological innovations in the sphere of information processing and transmission leads to a reorganization of public-financial relations, since their influences are quite impressive. Numerous scientists in their works note the significance of the impact of technological innovations. Such reflections are supported by the prospect of computer technologies to transform the telecommunications field and combine these technologies, resulting in the formation of such services as electronic communication, the provision of information in the form of text, audio and video 
files, social networks, etc. The proliferation of digital technologies gives rise to a discussion about the creation of the new socio-economic relations of the digital economy.

After considering various approaches to the establishment of socio-economic relations, formed on the basis of digital technologies, it becomes clear that at the present time there are not formulated sufficiently accurate, detailed statements on this matter. Most of the researchers focus on numerical characteristics and imply that at a certain point in achieving a number of numerical characteristics, the digital economy begins to dominate.

\subsection{The problems of Russia's transition to a digital economy}

Improvement of classical production spheres and service areas, related economic and logistical operations against the background of penetration of information technologies and digitalization of financial processes forms the basis for the development of new markets and the newest circumstances of the functioning of the market, as well as the latest approaches to analytics, modeling and management decision-making [9]. Formed as a result of economic modernization, "large data", along with the technologies for their consideration, become one of the main assets of the country and business. At the same time, the lack of physical boundaries in the digital space reveals the admission to a substantial array of such data to countless participants in the global space. The creation of state-owned projects for the formation of a new generation economy, containing problems of technology formation and implementation, analysis of "large data" and modeling, and introduction of new management methods, becomes a problem of strategic importance not only in the context of socio-economic welfare of countries, but also as a requirement of saving sovereignty for the background of globalization and the implementation of digital formation programs by other partners in the world market.

Order of the President of the Russian Federation from 09.05.2017 No. 203 "On the Strategy for the Information Society Formation in the Russian Federation for 2017-2030" declares that the formation of the digital economy is a strategically important issue for the Russian Federation in full, characterizing its competitiveness in the international arena .

The purpose of the state program for the formation of the digital economy is the formation in the Russian Federation of suitable coordination and regulatory conditions for the successful formation of institutions of the digital economy with the participation of the country, the state business society and the civil society and providing a rapid increase in the state housekeeper due to a high-quality change in the structure and management concept state financial assets, achieving the result of the "domestic financial cial miracle "in the conditions of the global digital ecosystem.

With the aim of forming a digital economy in the Russian Federation, a more optimal step is to form a number of industrial digital platforms managed by the relevant ministries or state corporations, which will focus on the main trends: road transport, telecommunications, electricity, information processing. Such platforms will make the necessary infrastructure basis for the extremely rapid formation of the digital economy and the dissemination of related technologies, and will provide an opportunity in the future to create a single digital space connecting all branches without exception. This kind of aspect will promote an impressive increase in the transparency, controllability and elasticity of the state economy.

This policy has both positive properties and negative ones. The advantages of this approach in the formation of the digital economy of the Russian Federation include:

- the accelerated development of infrastructure;

- a single digital space connecting all branches without exception;

- ease of maintenance, the formation and integration of digital platforms. 
The minuses are the big risk of digital monopolization of numerous sections of the economy, which will lead to the destruction of competition. The threat of increasing digital inequality between industries is also high.

The formation of the digital economy of the Russian Federation today is hampered by the latest threats, primarily:

- The problem of granting human rights in a digital society, including the presence of identification (correlation of a person with its digital image), the safety of digital user information, and also the issue of providing people's trust in the digital sphere;

- Threats to the individual, business and the country, coupled with trends towards the concept of complex hierarchical reference and telecommunications systems that use virtualization extensively, remote (cloud) data stores, and also heterogeneous technological processes of interconnection;

- Capacity building of external information and technological influence on the information infrastructure;

- The growth of computer crime, including international crime; delay from leading foreign countries in the formation of competitive information technologies;

- Dependence of the public-financial formation on the export policy of foreign countries;

- Insufficient effectiveness of academic research related to the formation of promising information technologies, insignificant level of implementation of Russian developments, and also unsatisfactory level of professional provision in the field of informational security.

\subsection{Prospects for the development of the digital economy in Russia and abroad}

As predicted by IDC [10], by 2018, a third of organizations currently entering the top twenty favorites in most industries will begin to feel significant competition from previously unidentified candidates and rebuilt "old" organizations using e-platforms with the purpose of forming the newest services and business models. It is understood that in 2018-2020. The industrial stage of increasing the international economy will come to an end and its subsequent formation will be realized under the increasing influence of cognitive conditions and productions based on the principles of lean production, additive, nano and biotechnologies. In accordance with this, the size of the data required for the formation and adoption of administrative decisions will grow; the composition of production management is reformatted according to the output of products and services; there will be changes in the concept of interaction between residents and business with municipal authorities.

The main conditions for the phase transition to a positive trajectory of public and financial formation are the following:

- implementation of the concept of e-government;

- mass emergence of products of the latest scientific and technological generation on the market (for example, the production of unmanned vehicles, etc.);

- increased use of 3D printers;

- the embodiment of the idea of building a "reasonable" and maximally eco-logical structure;

- distribution of various kinds of other and independent forms of employment, including outsourcing (accounting services, programming, etc.).

These conditions are combined with a reduction in costs in production and management through the use of digital economy platforms, which can be regarded as a product and electronic service complex. In the forefront of the conversation is about such platforms, as a 
special order of services, the collective use of resources, the selection of counterparties, ecommerce, payments, etc.

Thanks to IT today's production, the highest speeds and variety of services and product offerings are all the most inherent. For the latter, the rapid development and emergence of new products and the shortest period of their existence are characteristic. In the share of services, digital technological processes are ready to make the decision of standard issues with a huge amount of action significantly inexpensive, fast, comfortable and without intermediaries, an example of what such technological processes are considered as the Uber taxi application (the term "business" is included in the lexicon), electronic trading activity, Internet banking, etc. That is, in order to increase profitability in numerous areas of the economy, intermediaries can be replaced with automatic network services (a fairly wellfunctioning website or mobile application). Such organization of business makes it possible not only to significantly reduce the cost of services, but also leads to the newest structure of the economy, in which various figures of personal manufacture and inferior employment can exercise dominant importance. Crowdfunding technologies and crowdsourcing can also be regarded as the newest economic technological processes.

In 2017, the Organization for Economic Co-operation and Development (OECD) hosted a study that examined the potential of the digital economy in the OECD 2017 (OECD Digital Economy Outlook 2017). After the global financial crisis, the added value in the sector of reference and communication technologies (ICT), in general, decreased in the OECD in accordance with a single added value. Within the ICT section, the added value in telecom offers and the manufacture of PCs and electronics has decreased, but in the services of information technology (IT) there has been an increase, and in the release of software the value added remained unchanged.

In the coming years, it is expected that such diametrically opposed trends will be supported, which have been reflected in the OECD employment ICT, thus, as part of venture capital investments in ICT - an indicator of business expectations - returned to the 2000 level. The ICT sector remains the main engine of innovation, accounted for the most significant portion of companies' costs of R \& D in the OECD and more than one-third of all patent applications in the world.

Innovations controlled by data, the latest business modifications and digital applications have an impact not only on the science of this field, but also on the government itself, where these innovations are developed and introduced. Policy actions to support digital innovation tend to focus on innovation networks, access to finance and (secondary) application of information, but pay less attention to investments in ICT, knowledge-based capital and data considerations.

The influence of digital transformations is also expressed in the abolition and formation of jobs in various sectors, the emergence of new forms of work and changing the relief of trade, in particular, services. As a result, numerous states are reviewing labor laws and trade agreements. The potential of blockade technology depends on combating technical problems and social and political challenges. Blocking enables the transaction in the absence of any authorized persons. For example, bitcoin is a conventional monetary unit, based on the block system, regardless of any major bank or economic institution.

The use of the blockchain reveals the newest opportunities in numerous spheres, including in the economic sector, in education, the Internet, by reducing the price of transactions, simplifying accounting and providing performance obligations through smart contracts. Its capabilities will largely depend on the solution of technical problems and socio-political challenges such as the provision of the use of laws and the protection of order in the absence of any intermediary or the achievement of an accurate representation of how and to whom the legal responsibility lies in the case Damage to systems based on the blockchain [11]. 


\section{Results}

\subsection{Definition of IT strategy}

IT strategy is a plan for the formation of information systems in accordance with the company's development strategy, current and future business needs [12]. In the process of developing an IT strategy, the key characteristics of the information platform being developed are laid down in order to meet the following conditions:

- Flexibility - the system should be easily customizable for changes in internal business processes and the external environment;

- Standardization - various elements of the system must be compatible and meet the conditions of information security;

- Scalability - the system must take into account the increasing needs of the company;

- Economic efficiency - the application of this or another regulation should be justified economically;

- Independence - the customer does not have to be dependent on the suppliers of products / services, and there should not be a need for the content of his software development staff.

The connection between the strategic goals and objectives of the company and the strategy of informatization can be shown in the following way:

- The business strategy establishes the directions of formation of the main sphere of the company's work and the prerequisites for moving in this direction;

- Informatization strategy defines IT, which is necessary to support and optimize the business strategy, and demonstrates how these technological processes and systems can be implemented in the company.

IT strategy, on the one hand, is focused on the results formulated in the business strategy. On the other hand, the IT strategy establishes trends in the formation of IT in the company. In a similar way, the IT strategy is built on the basis of a business strategy. In the course of its development and implementation, it is possible to note the same stages as in the overall strategic plan: the study of the IT situation, the creation, implementation of strategy and strategic supervision in the IT sphere.

In a similar way, the strategy of informatization is prompted to establish a set of priority IT initiatives that will provide an opportunity to coordinate the information and scientific and technical complex of the company in a coordinated and coordinated manner with the interest of all departments on the basis of general conditions in order to achieve the strategic goals of the company. The research of information systems available in the company is carried out with the purpose of establishing their correlation between the multifunctional tasks of business at various stages of management.

The purpose of this kind of diagnostics is to determine the current state of IT-support for the sake of its subsequent formation in accordance with the developed IT strategy.

To perform the diagnostics, the following key tasks must be performed:

- Diagnostics of IT-support of key multi-functional business processes and control devices;

- Characteristics of IT costs.

- Characteristics of providing informative security;

- Analysis of IT infrastructure;

- Characteristics of the organizational provision of IT [13].

The development of the concept of IT formation should be based on a number of basic principles:

- IT should be a strategic component of the company's business architecture; 
- Satisfaction of the priority tasks of business: reducing costs, improving the manageability of the company, economic transparency;

- Protection of investments in IT: the introduction of systems that are less at risk of business strategy uncertainty;

- Balance between current and strategic objectives.

The real efficiency from automation of the company can be obtained to a large extent due to optimization of management actions in the company, management of operator actions and management of economic funds. Thus, the formation of an IT company must move according to 4 main trends:

1. Automatic automation of all the operator processes that provide cost reduction and improve the main performance characteristics of the company's business units;

2. The formation of a collective information system based on an integrated solution and effective procedures for the collection, processing and provision of data;

3. The formation of an IT infrastructure that satisfies progressive conditions according to the level of reliability and security;

4. Increase in the performance of users and IT staff.

The volume and timing of the implementation of projects are formed according to the results of an assessment of the current state of IT-support of the company, a detailed consideration of the results and the establishment of the direction of formation of the IT company. The project for the implementation of plans begins with the execution of a set of works, starting with the analysis and detailed planning of work in accordance with the single tasks of automating the business process within the framework of the IT formation strategy.

Elements of the Information Technology Strategy

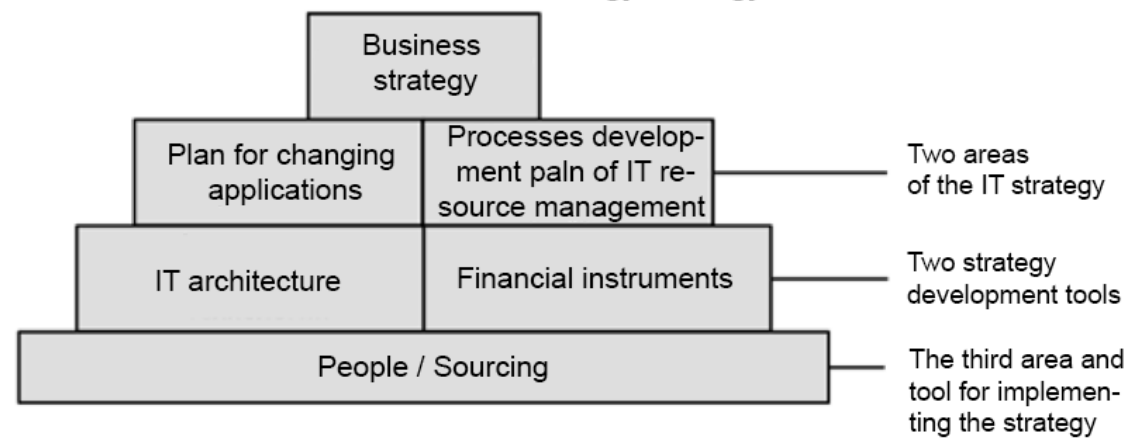

Strategy development process

\begin{tabular}{|c|c|c|c|}
\hline $\begin{array}{c}\text { Development of the } \\
\text { strategy for changing } \\
\text { the portfolio } \\
\text { of applications }\end{array}$ & $\begin{array}{c}\text { Development of the } \\
\text { strategy of IT } \\
\text { management } \\
\text { processes }\end{array}$ & $\begin{array}{c}\text { Development of a } \\
\text { strategy in the } \\
\text { field of personnel } \\
\text { and sourcing }\end{array}$ & $\begin{array}{c}\text { IT strategy } \\
\text { management }\end{array}$ \\
\hline
\end{tabular}

Fig. 1. Model of information technology strategy

Thus, a business strategy is considered as the basis for discussing and researching an IT strategy, regardless of whether it is in an obviously formulated form or not (the ways of solving this problem if there is no clearly formulated business strategy).

The next fact is that the IT strategy consists of two key elements: the strategy for modifying the portfolio of company application systems and the strategy for shaping the processes of managing IT resources of the company. Such a distribution can help management use different criteria for assessing the contribution of any of these areas of work of IT 
departments. For the development of the strategy, 2 main tools are used: the structure of the company's information technology and economic instruments. The structure means the limits of IT decisions at that time, when economic instruments are used to assess the likely settings associated with the implementation of the strategy. These are planning and implementation tools. The one and the other have all the chances to be formulated in a business language, and therefore have every chance to be the basis for a general discussion of the IT strategy by the business leadership.

The final component of the strategy is staff and a strategy for sourcing (the use of internal and external resources): this part of the IT strategy involves the provision of resources that are important for implementation.

The problems of planning the formation of IT strategies of the company makes sense to be divided into 3 separate documents - "IT Strategy", "IT Architecture" and "Project Implementation Plan", respectively. The preparation of these documents is based on the development and analysis of the discrepancy between the target state of the company's systems (that is, the state in which IT meets the requirements from the business, taking into account the possibilities for its formation) and the current state of IT systems.

\subsection{Implementation of IT strategy}

The level and extent of application of information technologies in their own work and integration into the Internet sphere are determined by the peculiarity of each company. The general strategy of formation chosen by the company is determined by a large number of conditions, including the company's mission and objectives, the position of the company in the market, the competitive advantages of the company, the range of products / services produced, industry characteristics of the company's functioning, the number and structure of relationships with buyers and suppliers, technological manufacturing processes, rival strategies, company potential, production and sales costs, management requirements. In turn, the strategy of integrating information technologies in the company's work should be consistent with the company's unified strategy in a certain market, and serve the achievement of the main goal of effective development of the company in a specific market space based on information technology.

The ratio of the two noted strategies of the company depends on the role that information technology plays and, in particular, using the innovative potential of the Internet environment in shaping the competitive advantages of the company in the market. An important condition is the degree of maturity of the company itself, its desire to introduce and use information technology. In addition, the rationality of the introduction of information technologies for the purpose of integration into the Internet environment directly depends on the readiness of contractors - buyers and suppliers creating the external environment of the company, for this kind of integration.

The company's desire to introduce information technologies reflects the degree of development of the organizational structure of the company, the formalization and systematization of business processes, the desire of the authorities, as well as several other characteristics. Thus, a huge number of domestic industrial companies are not ready to introduce information technologies into their own activities for a number of reasons:

- Economic - an elementary shortage of funds for the introduction of corporate information systems and the latest information technology, or a significant price for their service.

- Infrastructural - obsolete production special equipment, which eliminates the possibility of automation and integration of information technology in production,

- Organizational - insufficiently study able staff, lack of precise organizational structure. 
- Methodological - the difficulty in determining the financial result from the introduction of information technology. Although the enterprise is considered from the point of view of the implementation of the CIS (corporate information system), certain components of this approach can be applied to assess the maturity of the company for the purpose of integration into the Internet sphere.

Table 2. Role matrix / capabilities

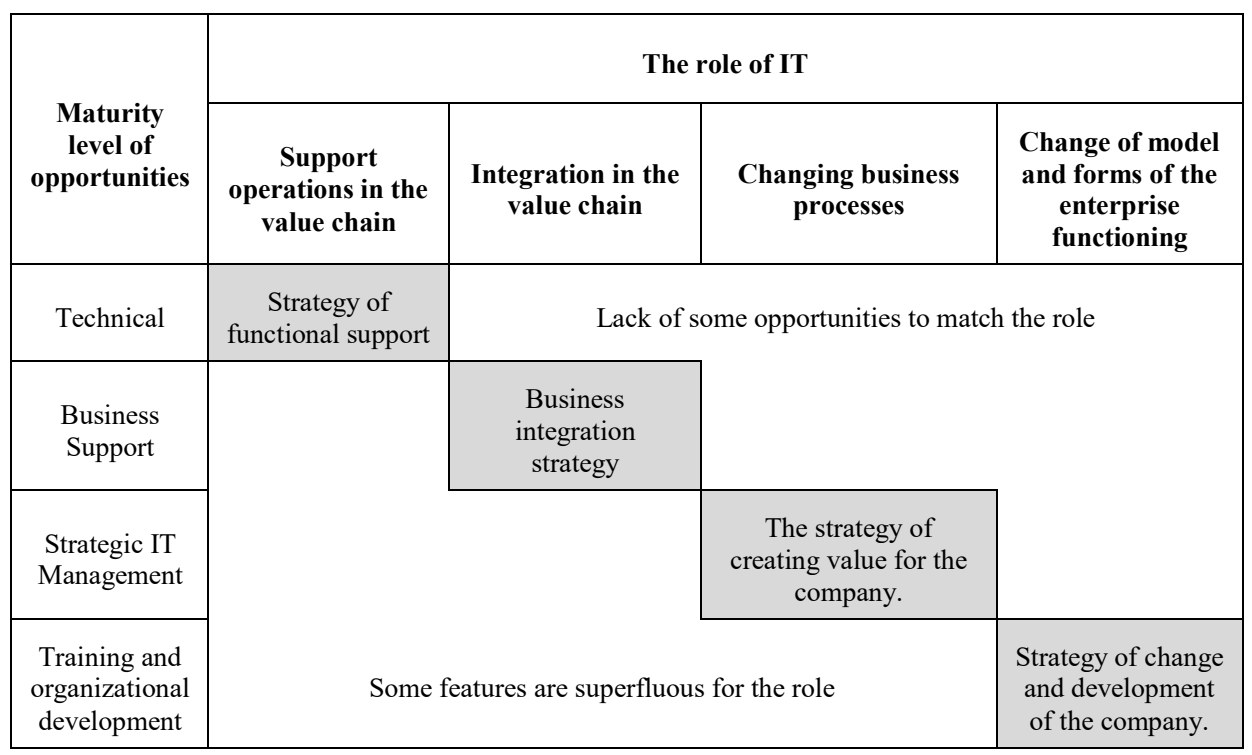

The level of maturity of information technology is determined by their importance in the work of the company, which can be established, based on the level of their responsibility in the value chain. It is possible to note 4 key roles, taking into account the contribution to the value chain predicted from informative technologies (any further stage includes the abilities of the previous one).

1. Support campaigns in the value chain;

2. Integration into the value chain;

3. Modification of business processes;

4. Modification of models and configurations of the company's functioning. From the definition of the importance of information technology in the company's activities are dependent on the subsequent steps to develop and implement the company's overall strategy [14].

Table 4. shows the increase in the maturity of the information technology capabilities of the company in relation to the maturity stages and their capabilities. The upper part of the table shows the degree of maturity, on the left side - the possibilities. Opportunities show the functions of IT in accordance with the management of company resources - industrial, professional, economic, relationships, etc. The table does not show the "zero" level of IT maturity, when information technology is almost not used in the company's activities. This level is still found in domestic companies. Matrix "capacity / level of maturity" can be used as a mechanism to describe IT strategies. The level of maturity in this case will be correlated with the IT values, and at the intersection it is possible to form "rational" types of strategies (see Table 2). These "rational" types of strategies for integrating information technologies reflect, first and foremost, a single vision and the concept of introducing information technologies in the company's operations: 
Strategy of functional support. The importance of IT in this strategy is limited only to technical assistance operations. This does not require a high level of IT maturity, it is sufficient to achieve a technical level of abilities. The role of IT is to implement technical solutions that meet the needs of the organization in supporting the elements of the entire value chain. With this IT strategy, you are not ready to fundamentally change business processes or models.

Business integration strategy. This strategy combines integration into the value chain and the opportunity to help the business. It is characterized by the unification of individual elements of processes with information technology. However, information technology is not entrusted with the task of fundamentally changing business processes and involving in strategic management.

The strategy of creating value for the company. This strategy is characterized by the most significant impact of information technology on strategic management issues, while IT is involved in changing business processes. In addition to supplying technical solutions and integrating from IT, it is necessary to change the business processes.

Strategy of change and development of the company. Information technology is given the largest mission, dictated by their significant contribution to the value chain. Information technologies acquire independent significance, are ready to make changes in the sphere of products and / or services, and also influence the geographic scope of the company's work, transforming the model of its functioning.

The matrix "role / capabilities" makes it possible to find the correlation between the roles of information technologies and the degree of maturity of their capabilities and sets the "coordinate system" for the purpose of assessing the application of information technology by the company in order to determine possible options for the actions of its management. The possibilities of applying the described approach are demonstrated on the example of a conditional company. The presented approach enables the company's management to substantiate the importance and functions of IT in a reasoned way and to create the necessary strategy for the integration of information technologies, coordinated with the overall development strategy, taking into account the peculiarities of the company's activities. Realization of a reasoned strategy of using information technologies will help to achieve the competitive advantages of the company and will provide an opportunity for stable development in today's markets.

\section{Conclusions and Discussions}

Expansion of economic relations among the leading states of the world, development of information technologies, mobile communications, as well as the need to reduce costs led to the emergence of such a phenomenon as a "digital economy". Under the digital economy, it is customary to understand the result of the transformation effect of the latest generalpurpose technology in the field of information and communication.

This transformation has affected the formation of numerous sectors of the economy and public activities, such as: the economic sector, industry, education, health, etc. In addition, the Internet system has increased people's abilities, allowing them to form and share their thoughts, accompanying the formation of new markets.

Methods for the formation of the "digital economy" turned out to be quite a lot, since any of them pursues the concept of the deepest integration of information technologies with the processes of the economy. The digital economy is created with an orientation toward the buyer, the area of sale and value, which is obliged to meet the quality of the service provided. The development of the information and technological complex of the company is to be realized on the basis of the developed IT strategy. The strategy guarantees the unification of the methodologies used in the company, increases the effectiveness of 
implementing changes in different nuances of the management concept, including when integrating the latest business processes, and also guarantees the greatest response from investments in information technology by allocating money to higher priority projects and initiatives in sphere of informatization. It should be taken into account that the absolute and timely implementation of the IT strategy for the formation of the company requires intensive management participation, which in many ways guarantees the result of strategic goals and the long-term success of the company in all areas.

As a result, the company acquires a strong, flexible and scalable IT infrastructure that allows processes such as project management, operational management, risk management, capital management and other business processes to be performed on a high-quality new level. IT infrastructure increases the effectiveness of information exchange among the company's structural divisions, the timeliness of decision-making and implementation of the issues assigned to each of these units, which is considered one of the most important factors of the company's success - its profitability, profitability, competitiveness.

\section{References}

1. J. Wetherbe, Information technology for management: Transforming organizations in the digital economy, (2008).

2. G. Valenduc and P. Vendramin, Work in the digital economy: sorting the old from the new, (2016).

3. Brand Finance, 'Brand Finance Global 500 2018'.

4. R. Kluver, Globalization, informatization, and intercultural communicatio, (2010).

5. McKinsey \& Company. [Online]. Available: https://www.mckinsey.com/ru/ourwork/mckinsey-digital. [Accessed: 01-Apr-2018].

6. M. Falk, Appl. Econ., 38(5), 533-547 (2006).

7. S. Grimes, Prog. Hum. Geogr., 27(2), 174-193 (2003).

8. I. V. Ilin, K. V. Frolov, and A. A. Lepekhin, in Proceedings of the 29th International Business Information Management Association Conference - Sustainable Economic Growth, Education Excellence, and Innovation Management through Vision 2020, 1157-1164 (2017).

9. V. V. Gloukhov, I. V. Ilin, V. I. Koposov, and A. I. Levina, Asian Soc. Sci., 10(24), 209 (2014).

10. IDC: The premier global market intelligence firm. [Online]. Available: https://www.idc.com/. [Accessed: 01-Apr-2018].

11. N. Vovchenko, A. Andreeva, A. Orobinskiy, and Y. Filippov, Eur. Res. Stud., 20(3B), 193 (2017).

12. D. Q. Chen, M. Mocker, D. S. Preston, and A. Teubner, MIS Q., 34(2), 233-259 (2010).

13. I. Ilin, O. Y. Iliashenko, and A. Levina, 'Application of service-oriented approach to business process reengineering', in Proceedings of the 28th International Business Information Management Association Conference, Vision, 768-781 (2016).

14. A. Saeed, R. A. Usmani, H. Akram, S. M. Saqlain, and A. Ghani, Eng. Technol. Appl. Sci. Res., 7(6), 2189-2193 (2017) 